- termination is under way for the third. The University of Texas and MD Anderson are still investigating one researcher, and say that ending another's employment is not warranted. Four of the researchers were accused of improperly sharing confidential information about grant applications, and one of sending at least one grant application containing proprietary information to a scientist in China, according to a redacted version of the letters.

Science and the Houston Chronicle also report that they have identified three further institutes that received letters from the NIH, concerning a total of eight researchers.

\section{What about other agencies?}

This February, a memo from the Department of Energy reportedly said the department was banning its employees, contracted scientists and grant recipients from participating in talentrecruitment programmes run by the governments of "sensitive" countries, over fears that participants could share government research.

The memo didn't specifically mention China, but since 2008, the country's Thousand Talents Plan has prompted thousands of Chinese engineers and scientists to return to China, many of them from the United States. Researchers are given prominent positions

and generous funding, and some maintain affiliations at institutions in both countries.

\title{
What about visas?
}

The US state department has also imposed new restrictions. Following a policy introduced last June, Chinese graduates wanting to studying robotics, aviation or high-tech manufacturing in the United States can no longer apply for five-year study visas; the policy allows these students to apply for one-year visas only.

\section{Is travel affected by the rising tensions?}

It seems so. Several scientific conferences in

\section{"Chinese} students are looking to the European Union for career opportunities." the United States have reported visa delays for Chinese nationals, including the Astronomical Data Analysis Software \& Systems conference in College Park, Maryland, last November. Of the 24 Chinese researchers who applied for the conference, only 6 were granted visas, says Peter Teuben, an astronomer at the University of Maryland in College Park who helped to organize the conference.

Pan told Nature that he has missed two conferences in the US this year, including the American Association for the Advancement of Science meeting - where he was to have collected the prestigious Newcomb Cleveland Prize for an outstanding paper published in the journal Science - because he was not granted a visa in time. "It is obviously more difficult to get a US visa [now]," says Pan.

He received a three-month, single-entry visa last month. In the past, he has obtained multientry visas for a year in less than a month. "The difficulty definitely causes obstacles for scientific collaboration between scientists in the US and other countries," he says.

\section{Are the tensions affecting science in China?}

Many Chinese scientists don't want to speak publicly about the situation. But Jay Siegel, dean of the School of Pharmacy at Tianjin University, says the country is less reliant on collaborating with the United States than it was a decade or two ago. Students and investors are looking to the European Union for career opportunities or business development, which is seen as more open and accepting of Chinese collaborations, says Siegel. If visa problems continue, Chinese researchers will try to strengthen their relationships with Europe. "They'll go where they're welcome." -

\section{Height's 'missing heritability' found}

\section{Analysis of 20,000 genomes reveals that rare gene variants can help to explain how the trait is inherited.}

\section{BY LINDA GEDDES}

$\mathrm{Y}$ ou need only to look at families to see that height is inherited - and studies of identical twins and families confirm that suspicion. But since the human genome was first sequenced nearly two decades ago, geneticists have struggled to fully identify the genetic factors responsible.

Many studies searching for the source of this heritability had focused on common gene variants. But even though researchers had identified hundreds of these common variants linked to height, each one had a tiny effect that together didn't amount to the genetic contribution predicted by family studies. This phenomenon, which occurs for many other diseases and traits, was dubbed missing heritability.

Now, a study suggests that most of the missing heritability for height and body mass index (BMI) can, as some researchers had suspected, be found in rare gene variants that had lain undiscovered until now.

"It is a reassuring paper because it suggests that there isn't something terribly wrong with genetics," says Tim Spector, a genetic epidemiologist at King's College London. "It's just that sorting it out is more complex than we thought." The research was posted to the bioRxiv preprint server on 25 March (P. Wainschtein et al. Preprint at bioRxiv https://doi. org/10.1101/588020; 2019).

\section{SCOURING THE GENOME}

To seek out the genetic factors that underlie diseases and traits, geneticists turn to megasearches known as genome-wide association studies (GWAS). These scour the genomes of, typically, tens of thousands of people or, increasingly, more than a million - for single-letter changes, or SNPs, in genes and elsewhere that commonly appear in individuals with a particular disease or that could explain a common trait such as height.

But GWAS have limitations. Because sequencing the entire genomes of thousands of people is expensive, GWAS themselves scan only a strategically selected set of SNPs, perhaps 500,000 , in each person's genome. That's only a snapshot of the roughly six billion nucleotides - the building blocks of DNA - strung together in our genome. And these 500,000 common variants would have been found from sequencing the genomes of just a few hundred people, says Timothy Frayling, a human geneticist at the University of Exeter, UK.

A team led by Peter Visscher at the Queensland Brain Institute in Brisbane, Australia, decided to investigate whether rarer SNPs than those typically scanned in GWAS might explain the missing heritability for height and BMI. They turned to whole-genome sequences - complete readouts of all 6 billion bases - of 21,620 people. (The authors declined to comment on the preprint, because it is under submission at a journal.)

They relied on the simple principle that all people are related to some extent — albeit distantly - and that DNA can be used to calculate degrees of relatedness. Then, information on the people's height and BMI could be combined to identify both common and rare SNPs that might be contributing to these traits.

Say, for instance, that a pair of third cousins is closer in height than a pair of second cousins is 
$z$ in a different family: that's an indication that the 嵌 third cousins' height is mostly down to genetics, and the extent of that correlation will tell you by S how much. "They used all of the genetic infor\on mation, which enables you to work out how 옹 much of the relatedness was due to rarer things as well as the common things," says Frayling.

As a result, the researchers captured genetic differences that occur in only 1 in 500 , or even 1 in 5,000, people.

And by using information on both common and rare variants, the researchers arrived at roughly the same estimates of heritability as those indicated by twin studies. For height, Visscher and colleagues estimate a heritability of $79 \%$, and for BMI, $40 \%$. This means that if you take a large group of people, $79 \%$ of the height differences would be due to genes rather than to environmental factors, such as nutrition.

\section{COMPLEX PROCESSES}

The researchers also suggest how the rare variants might be contributing to physical traits. Tentatively, they found that these variants were slightly enriched in protein-coding regions of the genome, and that they had an increased likelihood of disrupting these regions - which might be how they influence height, notes Terence Capellini, an evolutionary biologist at Harvard University in Cambridge, Massachusetts. The rarity of the

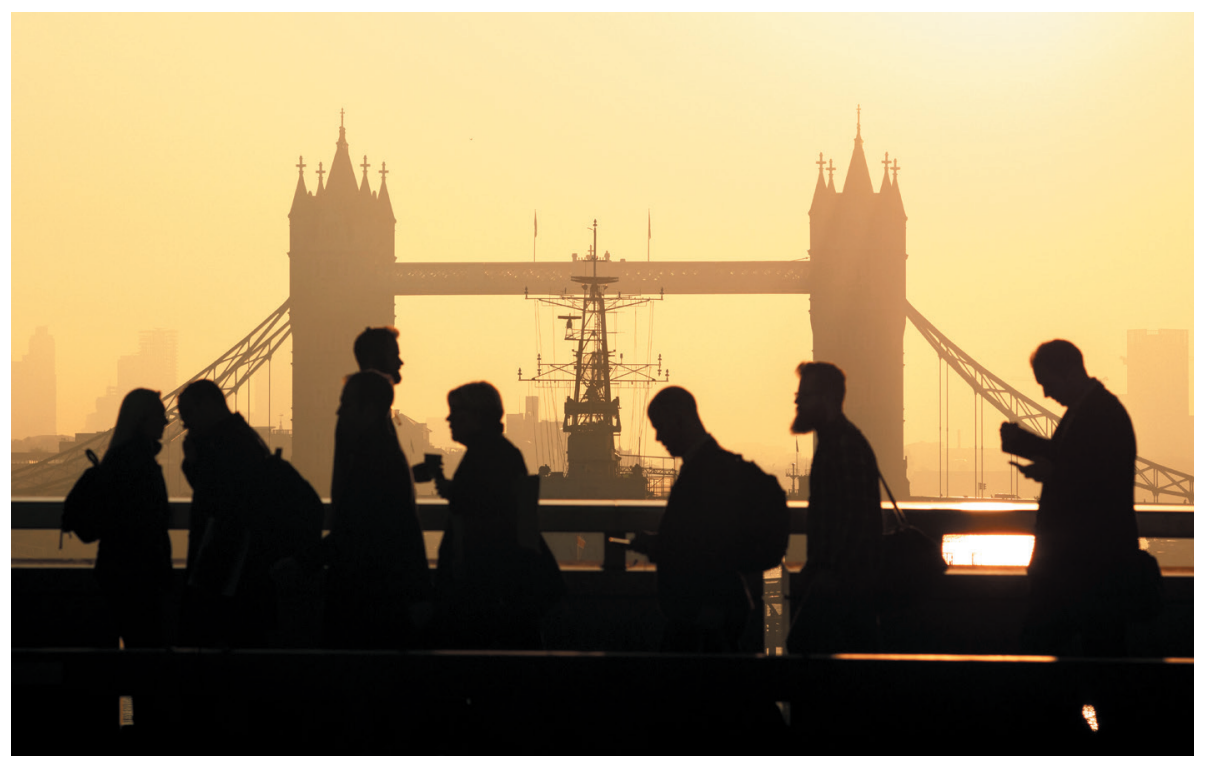

Height is inherited through a mixture of common and rare genetic variants.

variants also suggests that natural selection could be weeding them out, perhaps because they are harmful in some way.

The complexity of heritability means that understanding the roots of many common diseases - necessary if researchers are to develop effective therapies against them - will take considerably more time and money, and it could involve sequencing hundreds of thousands or even millions of whole genomes to identify the rare variants that explain a substantial portion of the illnesses' genetic components.

"The next stage is to go and work out which of these rare variants are important for traits or diseases that you want to get a drug for," says Spector.

\section{npj|Parkinson's Disease}

\section{Call for Papers}

Highlighting the most important scientific advances in Parkinson's disease research spanning the motor and non-motor disorders of Parkinson's disease

npj Parkinson's Disease is an open access, online-only, international peerreviewed journal. The journal publishes original basic science, translational, and clinical research related to Parkinson's disease, including anatomy, etiology, genetics, cellular and molecular physiology, neurophysiology, epidemiology and therapeutic developments and treatments.

Submit your next manuscript and benefit from:

- High visibility and wide dissemination

- Global reach and discoverability via nature.com

- Compliance with open access funding mandates

- Comprehensive and rigorous peer review by experts in your field

- Inclusion in PubMed and Web of Science

In partnership with

Parkinson's

Foundation

\section{EDITORS-IN-CHIEF}

Dr David Sulzer

Columbia University, USA

Professor K Ray Chaudhuri

King's College London, UK

\section{ADVISORY EDITOR}

Professor Stanley Fahn

Columbia University, USA

Part of the Nature Partner Journals series

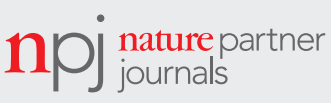

